\title{
USE OF HIGH INTENSITY REFLECTIVE SHEETING IN LIEU OF EXTERNAL LIGHTING OF OVERHEAD ROADWAY SIGNS
}

\author{
Fan $\mathrm{Ye}^{1}$, Paul J. Carlson ${ }^{2}$, Mike N. Jackson ${ }^{3}$ \\ ${ }^{1}$ Dept of Civil Engineering, Ohio Northern University, United States \\ ${ }^{2}$ Texas A\&M Transportation Institute, Texas A\&M University, United States \\ ${ }^{3}$ Allen E. Paulson College of Engineering and Information Technology, \\ Georgia Southern University, United States
}

Submitted 23 December 2015; resubmitted 12 April 2016; accepted 27 April 2016; published online 16 January 2017

\begin{abstract}
Overhead guide sign lighting has been used by many agencies to improve visibility. However, the availability of newer and more efficient retroreflective materials has created a new challenge for state transportation agencies going through sign sheeting upgrade programs and considering the need for using sign lighting, as there is no existing answer regarding whether upgraded sign sheeting itself can meet drivers' nighttime visibility demands without external sign lighting. The purpose of the paper is to investigate whether high intensity reflective sheeting can be used to replace overhead guide sign lighting. The conclusion of the study provided a guidance for agencies to adopt their current sign lighting policy. A luminance computation model is used in the paper to calculate overhead guide sign legend luminance under various situations, including different sign lighting technologies, different geometrics and overhead guide sign locations, and different amounts of sign dirt and sign aging. By comparing the calculated luminance of a specific overhead guide sign at a specific situation with the legibility luminance levels required by older drivers, sign lighting needs are assessed. In addition, a life-cycle cost spreadsheet is developed and used to calculate the cost of replacing the current sign sheeting with high reflective sheeting and the cost of installing/upgrading sign lighting. Eventually, the most cost effective approach to maintain overhead guide luminance is discussed.
\end{abstract}

Keywords: sign lighting; visibility; retroreflective sign sheeting; overhead guide signs; sign legibility.

\section{Introduction}

Effective highway signage is an important component to driver decision making, comfort, and safety (Carlson, Hawkins 2003). Given the high number of elderly drivers (in 2013, about $14 \%$ of the total drivers in US was older than 65 and the percentage has a trend of getting larger in the future), nighttime visibility of highway signage is important. Overhead sign lighting has been used by many agencies to ensure overhead guide sign visibility. However, the availability of newer and more efficient retroreflective materials has created a new challenge for transportation agencies in considering the need for sign lighting. There is a nationally general consensus in US that sign lighting is not needed for overhead guide signs with high intensity (in this paper, 'high intensity' refers to sheeting materials with high reflective properties, especially prismatic sheeting) reflective sheeting in rural areas; but in developed areas or along highways with unique geometries, there is a concern about removing or turning off overhead guide sign lights. In addition, a couple of recent surveys of state transportation agencies have shown a trend away from the use of overhead guide sign lighting when upgrading to more retroreflective sheeting materials (Jackson et al. 2013). Many agencies are interested in determining whether high intensity reflective sheeting can be used to replace overhead sign lighting, i.e., whether it can perform and meet retroreflectivity standards, whether it can satisfy elderly drivers' visibility demands at night; and whether it is costeffective.

Some relevant researches have been conducted on the visual performance of overhead signs using various sheeting materials with and without external sign lighting. For instance, Bullough et al. (2010) summarized previous studies regarding the effectiveness of different materials on sign visibility. The authors also compared the legibility of unlighted signs to lighted signs in an urban area of New Jersey using the relative visual performance model and found that the measured unlighted 
signs was similar to that of the signs equipped with sign lighting. Indiana Department of Transportation also developed an evaluation in 2009 to assess the feasibility of using overhead guide signs on freeways without lighting during nighttime (INDOT 2009; FHWA 2009). By comparing the conspicuity, legibility, and appearance of selected signing materials in nine legend-background combinations, the evaluation concluded that it was feasible to eliminate the lighting of overhead guide signs by using prismatic Type IX, VIII or IV legends on Type IV backgrounds (all sheeting types in the paper are based on the type designation by the American Society for Testing and Materials; see more details in ASTM D4956-09e1:2009). However, those research studies were conducted with a specific roadway geometry and limited scenarios, which leave other agencies hesitation to generalize and directly adopt the previous study conclusions.

Meanwhile, when transportation engineers refer to the current standards and specifications, they have found little to no assistance with such considerations. There are three applicable national policies and guidelines related to the nighttime visibility of overhead guide signs: Manual on Uniform Traffic Control Devices for Streets and Highways - MUTCD (FHWA 2009), Roadway Lighting: Design Guide (AASHTO 2005), and Illuminating Engineering Society of North America - IESNA (2001). However, none of them include warrants or guidelines to determine if lighting is needed. Beyond the question of whether sign lighting is needed or not, there is also a conflict between the MUTCD and the other two guidelines with respect to the suggested lighting levels. The required luminance used to set the MUTCD minimum maintained retroreflectivity levels are much lower than the values used by AASHTO (2005) and IESNA (2001). Another limitation of those policies and guidelines exists in the older drivers' demands of reading guide signs clearly at night. There is no specific consideration of sign luminance levels needed for older drivers.

Without guidelines for providing effective nighttime performance of overhead guide signs as a function of site-specific situations and covering elderly drivers' demands of reading guide signs clearly at night, sitespecific research is needed to address whether high intensity reflective sheeting is a safe and effective substitute for lighting on overhead signs in specific locations. The purpose of the paper is to identify if high performing retroreflective sign sheeting can replace the need for sign lighting; and if not, then determine where overhead guide signs with lights are needed. In the study, the authors model the visibility of overhead signs using luminance as the primary performance metric, and calculated sign legend luminance by a luminance computation model under various situations, including different sign lighting technologies, geometrics and sign locations, and amounts of sign dirt and sign aging. By comparing the calculated luminance of a specific sign at a specific situation with the legibility luminance levels required by older drivers, sign lighting needs are assessed. In addition, an analysis of the costs associated with upgrading sign sheeting and sign lighting is performed.

\section{Background of Minimum Required Luminance Levels}

In the paper, the authors use the human factors research from previous overhead guide sign research conducted at Texas A\&M Transportation Institute (TTI) for the Federal Highway Administration - FHWA (Holick, Carlson 2008). This previous work identifies the luminance needed for legibility. The minimum luminance needed for overhead guide signs was determined at legibility indices ranging from $40 \mathrm{ft} /$ inch $(4.8 \mathrm{~m} / \mathrm{cm})$ to $20 \mathrm{ft} /$ inch $(2.4 \mathrm{~m} / \mathrm{cm})$, in $10 \mathrm{ft} /$ inch $(1.2 \mathrm{~m} / \mathrm{cm})$ intervals for elderly drivers and for complex visual conditions that include glare from oncoming low beam headlamps and fixed roadway lighting. Since the MUTCD now uses a legibility guideline of $30 \mathrm{ft} /$ inch $(3.6 \mathrm{~m} / \mathrm{cm})$ of letter height, $30 \mathrm{ft} /$ inch $(3.6 \mathrm{~m} / \mathrm{cm})$ was also selected as the legibility index for this study. The resulting data for $30 \mathrm{ft} /$ inch $(3.6 \mathrm{~m} / \mathrm{cm})$ legibility index are summarized in a tabular form (Table 1), divided by roadway lighting condition (on or off) and presence of glare (on or off). The research determined that the white legend luminance needed for legibility was nearly the same regardless of whether the background color was green or blue.

Table 1. Luminance requirements for guide sign legends $\left[\mathrm{cd} / \mathrm{m}^{2}\right]$ (legibility index $=30 \mathrm{ft} /$ inch or $3.6 \mathrm{~m} / \mathrm{cm}$ )

\begin{tabular}{|c|c|c|c|c|}
\hline \multirow{2}{*}{$\begin{array}{c}\text { \% driver } \\
\text { accommodation }\end{array}$} & \multicolumn{2}{|c|}{ Roadway lighting } & \multicolumn{2}{c|}{ No lighting } \\
\cline { 2 - 5 } & Glare off & Glare on & Glare off & Glare on \\
\hline 10 & 1.50 & 2.07 & 0.30 & 0.60 \\
\hline 25 & 2.07 & 3.70 & 0.50 & 1.13 \\
\hline 50 & 2.50 & 4.73 & 0.93 & 2.13 \\
\hline 75 & 4.06 & 7.47 & 1.90 & 3.37 \\
\hline 85 & 8.70 & 9.80 & 2.70 & 7.81 \\
\hline 95 & 20.37 & 23.03 & 5.41 & 14.73 \\
\hline 98 & 22.82 & 27.68 & 7.25 & 21.00 \\
\hline
\end{tabular}

${ }^{*}$ Note: '\% driver accommodation' refers to the percentage of drivers who can read the sign.

In addition, for overhead guide signs, the minimum legend size for destinations is 16-inch uppercase and 12-inch lowercase Series E (Modified) alphabet (FHWA 2009). Therefore, a distance of $480 \mathrm{ft}(146.3 \mathrm{~m})$ between vehicles and overhead signs is reasonable for study in terms of the legibility index of $30 \mathrm{ft} / \mathrm{inch}(3.6 \mathrm{~m} / \mathrm{cm})$. The cumulative distribution graph on how much luminance is needed to accommodate the various percentages of the study sample for a legibility index of $30 \mathrm{ft} /$ inch $(3.6 \mathrm{~m} / \mathrm{cm})$ is shown in Fig. 1. Using Fig. 1, it is possible to develop the luminance values needed to accommodate the various percentages of the study sample.

The information in Fig. 1 describes how much luminance is needed for elderly drivers (age 55 and older) to read guide signs at a distance coinciding with the requirements of the MUTCD (FHWA 2009). To accommodate nearly all older drivers, one would need to provide luminance levels indicative of the levels shown at the $100 \%$ accommodation level. However, transpor- 


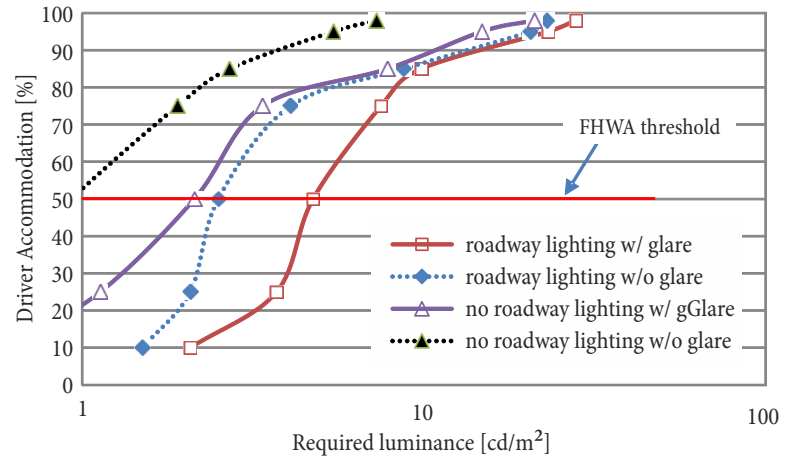

Fig. 1. Legend luminance required for guide signs (legibility index $=30 \mathrm{ft} /$ inch or $3.6 \mathrm{~m} / \mathrm{cm}$ )

tation agencies rarely design to accommodate all road users as the cost would be prohibitive. For reference, the FHWA chose to use the 50th percentile levels in their decisions concerning the development of minimum retroreflectivity levels for the MUTCD.

\section{Luminance Computation Model for Signs}

Using a luminance computation model, by defining sheeting material type, headlamp type, sign position, sign height, geometry of the roadway and luminance by sign lighting, supplied luminance of signs can be calculated. The effects of weather, dirt and age degradation are also included in the model. Based on sign retroreflectivity measurements and historical weather data in a specific location, dirt and weather adjustment factors were derived and used in the model. Meanwhile, the age degradation factor, which was derived from TTI's long-term weathering test on retroreflective sign sheeting products, was adopted to quantify the effect of sheeting age on sign luminance - see Jackson et al. (2013) for more details about the adjustment factors. Since sign luminance is determined by many influencing factors (all the inputs to the model), it is economically infeasible to measure it under all types of scenarios. Therefore, the luminance computation model is a valuable way to evaluate the supplied luminance under many different conditions.

The luminance computation model used for this effort is an extension of a computational model TTI developed for earlier research on sign visibility (Carlson, Hawkins 2003), with enhancements to account for dirt, weather, sign degradation, sign lighting, newer sign sheeting materials, and updated vehicle headlamps. The calculation procedures are listed in Fig. 2 - see Jackson et al. (2013) for step-by-step explanations.

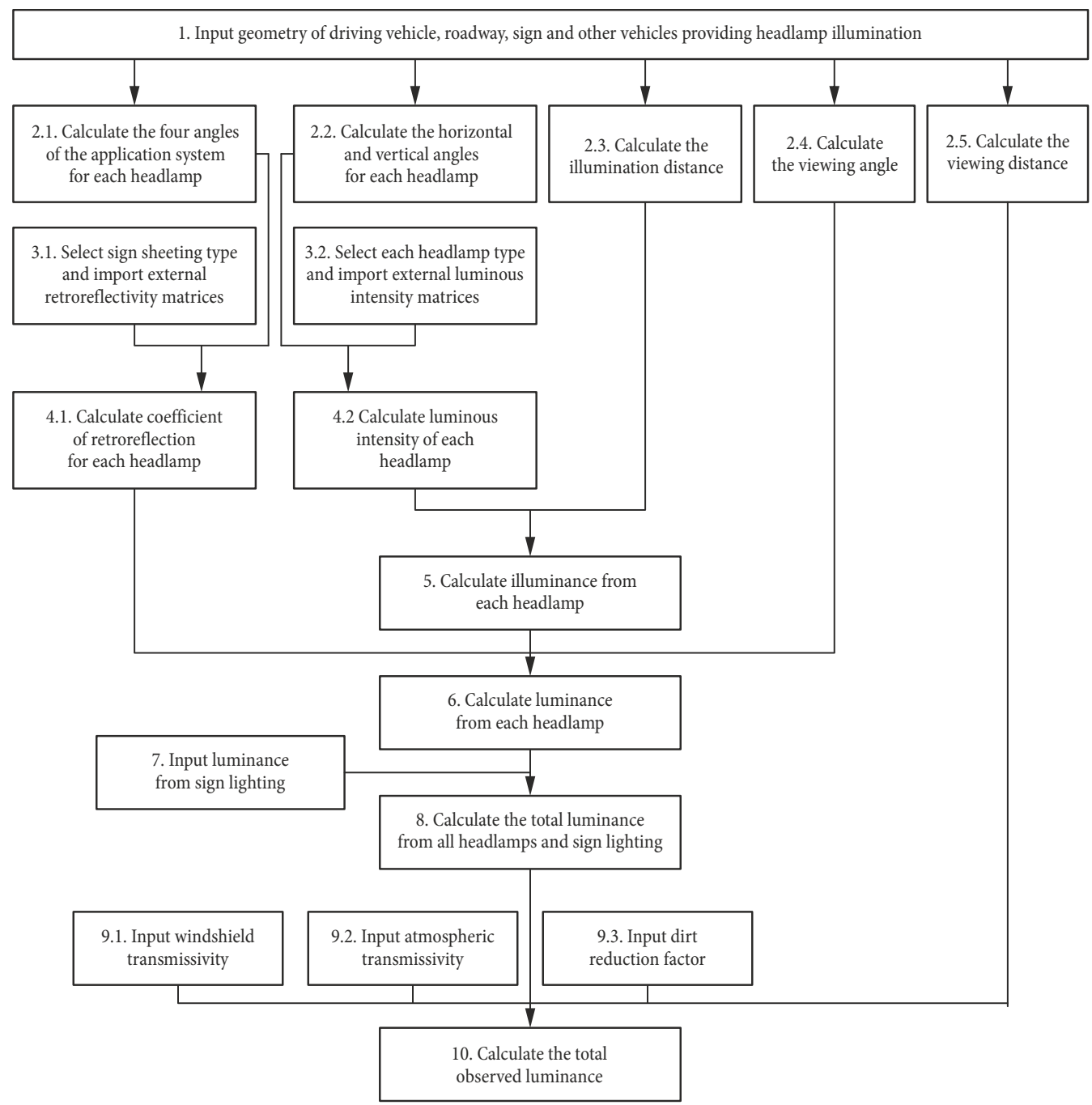

Fig. 2. Flow chart of calculation procedures in the luminance computation model 


\section{Model Design and Analysis}

With the steps of the model described in Fig. 2, the model can be used to estimate sign luminance in terms of different sign-vehicle geometry, sign type, sheeting material, sheeting age and vehicle type. For the purpose of illustration, some typical situations are selected. For overhead guide signs, the height of the sign (from center of the sign to the ground) is assumed to be $23 \mathrm{ft}(7 \mathrm{~m})$, and the sign is above the middle of a driving lane. Two vehicle types were included in the study: a passenger car and a light truck (or SUV). Their dimensions are listed in Table 2. Three types of sheeting materials are used in the study: Type IV, VIII and XI as prismatic sheeting, and Type III as a beaded material. Vehicle headlamps are US2004 and US2011 - i.e., use the 50th percentile luminous intensities of low-beam headlamps on model year 2004 and 2011 passenger vehicles in the US (Schoettle et al. 2004; Schoettle, Flannagan 2011). Lane width is set as $12 \mathrm{ft}(3.7 \mathrm{~m})$, and the vehicle is assumed to be always driving in the middle of a lane. In addition, the distance between overhead signs and vehicles is set to be $480 \mathrm{ft}$ $(146.3 \mathrm{~m})$ based on the legibility index of $30 \mathrm{ft} / \mathrm{inch}$ $(3.6 \mathrm{~m} / \mathrm{cm})$ as stated before. Therefore, supplied luminance values are calculated for various scenarios using the luminance computation model. By comparing the supplied luminance with the required legibility luminance, we can assess the adequacy of the sign performance in terms of nighttime legibility.

The results over time (i.e., based on different sheeting ages) are summarized in Fig. 3 for passenger cars, and Fig. 4 for light trucks. It needs to be noted that the dash lines in the figures are the 50th percentile minimum luminance demands (legibility index $=30 \mathrm{ft} / \mathrm{inch}$ or $3.6 \mathrm{~m} / \mathrm{cm}$ ) at the different ambient conditions from Fig. 1. Three ambient conditions are selected for analysis: one urban condition (roadway lighting with glare) and two rural conditions (no roadway lighting with and without glare), with the according threshold luminance levels as $4.7,2.1$, and $0.9 \mathrm{~cd} / \mathrm{m}^{2}$ for those three conditions. From the values, it is obvious that with more ambient background visual clutter and glare, drivers have higher visual demands on overhead guide signs.

From Figs 3 and 4, using US2011 as vehicle headlamps in the model leads to higher luminance than using US2004. Drivers in passenger cars attain more overhead guide sign luminance than those in light trucks. For light trucks, the driver's eyes are placed higher from the headlamps, which leads to larger observation angles.

For the conditions considered, the luminance of prismatic sheeting (Type IV, VIII and XI) is higher than that of the beaded materials (Type III). Type VIII sheeting is brighter than Type IV, and Type XI sheeting is brighter than Type VIII. The data in Figs 3 and 4 show that Type VIII and XI sheeting can be used without replacement for at least 20 years in any of the conditions (except dew conditions, which sign lighting can overcome), but Type III and Type IV sheeting materials are not adequate for overhead guide sign legends in urban areas considering their brightness after 20 years, adequate in rural areas though. However, if induction/LED luminaires (they are the common types of sign luminaires) are used as sign lighting, sign luminance increases significantly. Using the initial luminance provided by an induction luminaire of $9.5 \mathrm{~cd} / \mathrm{m}^{2}$ and the annual light loss factor of 0.97 - measured at TTI riverside campus, see more details in Jackson et al. (2013) - the supplied luminance is shown in Fig. 5 for Type III and Type IV sheeting. As noted, both figures show the luminance for a light truck, as it requires larger luminance for drivers than a passenger car. The supplied luminance in terms of LED luminaires is not plotted here as LED provides larger luminance than induction light.

From Fig. 5, it is found that Type III and Type IV sheeting materials can be used without replacement for more than 20 years in any condition (both urban and rural areas), when the sign is lit by induction or LED luminaires. Furthermore, it is possible that the induction or LED fixture can be dimmed from the maximum output and will still be adequate for up to 20 years.

The above luminance analysis is based on straight and flat roadways, i.e., no horizontal or vertical curvature for roadway geometry. However, horizontal curves can have significant effects on sign luminance. In order to study the breakpoint in terms of curve radius where sign lighting is needed, additional analyses are completed using varying radii. By running the luminance computation model for a light truck with US2011 headlamps and sheeting materials up to 20 years old, the supplied luminance of all sheeting types is calculated and compared to the demand luminance in urban areas (with roadway lighting and glare) and rural areas (without roadway lighting and glare). The breakpoint radii are achieved when the supplied luminance reaches a point equal to the demand luminance. Table 3 shows the breakpoint radii of curves for different sheeting types in rural and urban areas. As shown in the table, two relative locations of the vehicle and sign are considered for the analysis: both the vehicle and sign are in the curve; the vehicle is on the approach tangent and the sign is in the curve with three different distances to the Point of Curve (PC).

The breakpoint radii in the table represent the condition at which either a more efficient sign sheeting material is needed or sign lighting is needed. Please note that according to the results in Table 3, both sheeting materials Type III and IV cannot produce the luminance required in urban areas for the conditions studied.

Table 2. Vehicle dimensions for analysis

\begin{tabular}{|l|c|c|c|c|c|}
\hline \multicolumn{1}{|c|}{ Vehicle type } & Headlamp height & Driver's eye height & Headlamp separation & Driver's eye setback & Driver's eye offset \\
\hline Passenger car & $2.0 \mathrm{ft}(0.6 \mathrm{~m})$ & $3.5 \mathrm{ft}(1.1 \mathrm{~m})$ & $4.0 \mathrm{ft}(1.2 \mathrm{~m})$ & $4.5 \mathrm{ft}(1.4 \mathrm{~m})$ & $1.5 \mathrm{ft}(0.5 \mathrm{~m})$ \\
\hline Light truck & $2.8 \mathrm{ft}(0.9 \mathrm{~m})$ & $4.8 \mathrm{ft}(1.5 \mathrm{~m})$ & $4.4 \mathrm{ft}(1.3 \mathrm{~m})$ & $7.2 \mathrm{ft}(2.2 \mathrm{~m})$ & $1.3 \mathrm{ft}(0.4 \mathrm{~m})$ \\
\hline
\end{tabular}



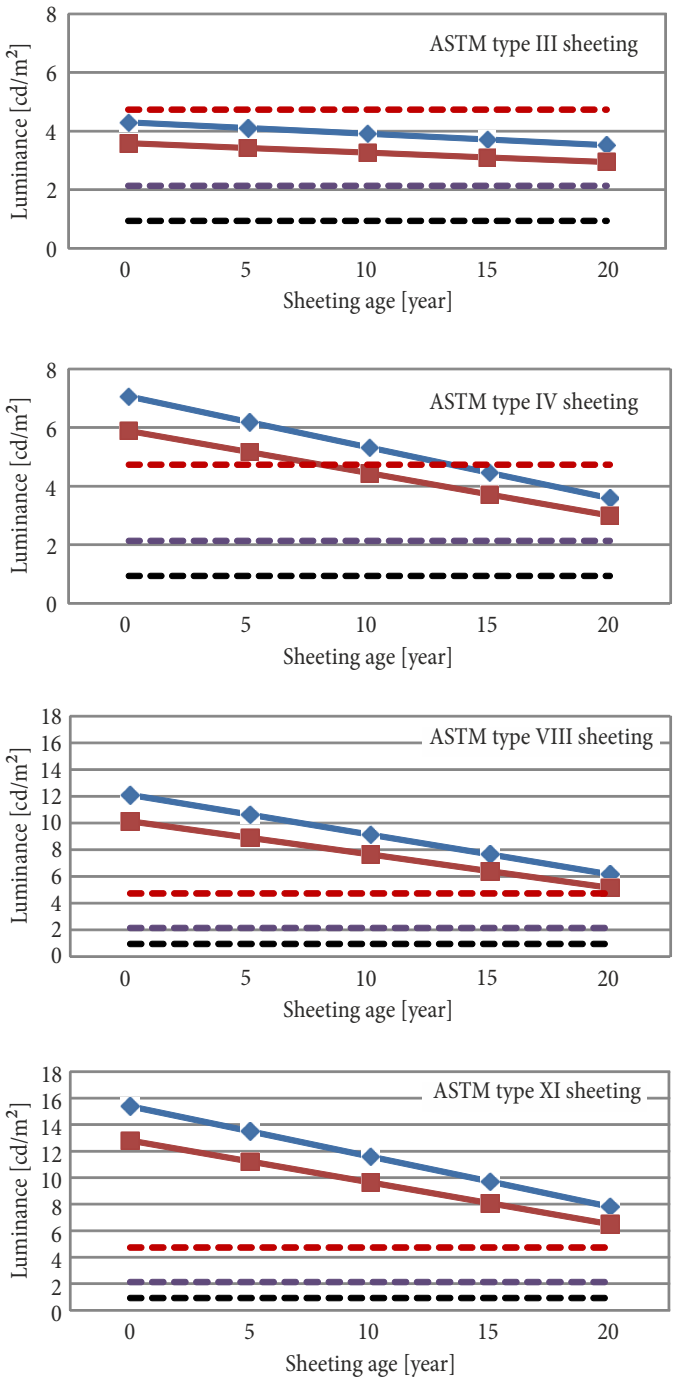

_ supplied luminance with US2011 headlamp

- - supplied luminance with US2004 headlamp

- - demand luminance with roadway lighting and glare

- _ demand luminance without roadway lighting but with glare

-_ demand luminance without roadway lighting and glare

Fig. 3. Supplied luminance vs. legibility luminance for passenger cars

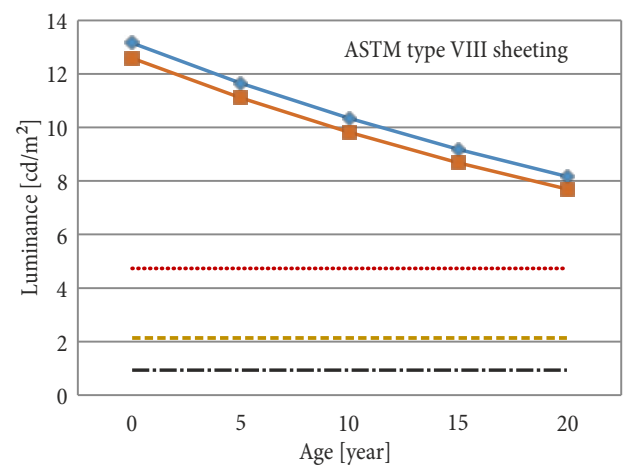

$\multimap \_$supplied luminance with US2011 headlamp and induction light

- - supplied luminance with US2004 headlamp and induction light

........... demand luminance with roadway lighting and glare
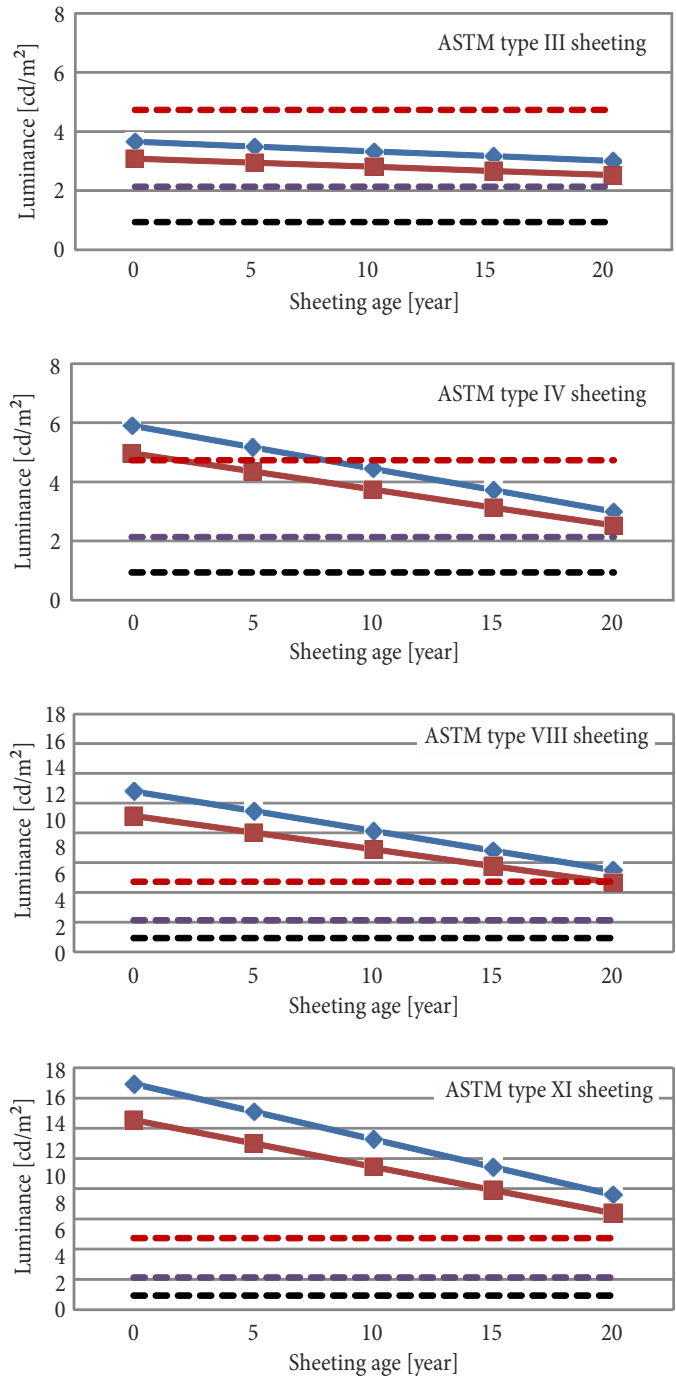

— supplied luminance with US2011 headlamp

$\rightarrow$ supplied luminance with US2004 headlamp

- - demand luminance with roadway lighting and glare

- - demand luminance without roadway lighting but with glare

- - demand luminance without roadway lighting and glare

Fig. 4. Supplied luminance vs. legibility luminance for light trucks

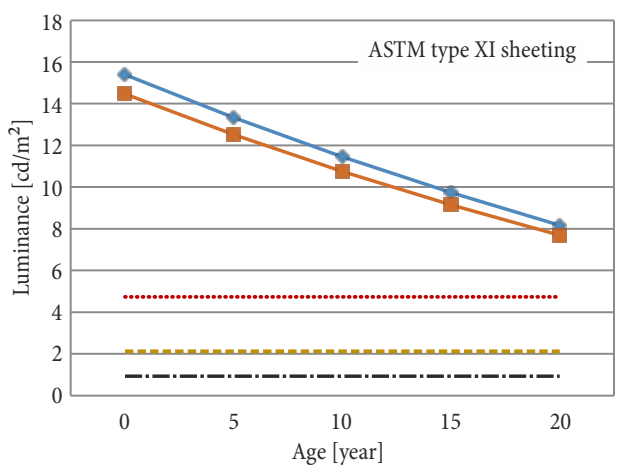

----- demand luminance without roadway lighting but with glare -. - demand luminance without roadway lighting and glare

Fig. 5. Supplied luminance with induction lights vs. legibility luminance for trucks 
Table 3. Breakpoint radii of horizontal curves in both rural and urban areas

\begin{tabular}{|l|c|c|c|c|}
\hline \multirow{2}{*}{ Legend sheeting } & \multirow{2}{*}{ Both vehicle and sign in curve } & \multicolumn{3}{|c|}{ Sign in curve (distance from PC) } \\
\cline { 3 - 5 } & & $250 \mathrm{ft}(76.2 \mathrm{~m})$ & $300 \mathrm{ft}(91.4 \mathrm{~m})$ & $350 \mathrm{ft}(106.7 \mathrm{~m})$ \\
\hline \multicolumn{5}{|c|}{ Rural area } \\
\hline Type III & $925 \mathrm{ft}(281.9 \mathrm{~m})$ & $200 \mathrm{ft}(61.0 \mathrm{~m})$ & $335 \mathrm{ft}(102.1 \mathrm{~m})$ & $470 \mathrm{ft}(143.3 \mathrm{~m})$ \\
\hline Type IV & $920 \mathrm{ft}(280.4 \mathrm{~m})$ & $335 \mathrm{ft}(102.1 \mathrm{~m})$ & $450 \mathrm{ft}(137.2 \mathrm{~m})$ & $595 \mathrm{ft}(181.4 \mathrm{~m})$ \\
\hline Type VIII & $810 \mathrm{ft}(246.9 \mathrm{~m})$ & $330 \mathrm{ft}(100.6 \mathrm{~m})$ & $420 \mathrm{ft}(128.0 \mathrm{~m})$ & $510 \mathrm{ft}(155.4 \mathrm{~m})$ \\
\hline Type XI & $880 \mathrm{ft}(268.2 \mathrm{~m})$ & $370 \mathrm{ft}(112.8 \mathrm{~m})$ & $460 \mathrm{ft}(140.2 \mathrm{~m})$ & $555 \mathrm{ft}(169.2 \mathrm{~m})$ \\
\hline \multicolumn{5}{|c|}{ Urban area } \\
\hline Type III & \multicolumn{5}{|c|}{$\mathrm{n}$} & $1930 \mathrm{ft}(588.3 \mathrm{~m})$ \\
\hline Type IV & $3650 \mathrm{ft}(1112.5 \mathrm{~m})$ & $980 \mathrm{ft}(298.7 \mathrm{~m})$ & $1410 \mathrm{ft}(429.8 \mathrm{~m})$ \\
\hline Type VIII &
\end{tabular}

The results in Tables 3 provide the information needed to develop a simple and conservative recommendation for when sign lighting is needed at curves. For instance, if Type XI material is used for overhead sign legends, then sign lighting would be needed in rural areas when the curve has a radius of $880 \mathrm{ft}(268.2 \mathrm{~m})$ or less. In urban areas sign lighting would be needed when the curve has a radius of $2500 \mathrm{ft}(762 \mathrm{~m})$ or less. Less restrictive criteria could be developed for other conditions where the vehicle is on the approach tangent and the sign is in the curve.

\section{Life-Cycle Cost Analyses}

The objective of the life-cycle cost analysis is to compare the cost of installing an overhead sign light to the cost of replacing the current sign sheeting with high reflective sheeting, as well as the costs of different combinations of sign lighting and sheeting materials based on the demanded legibility luminance. Costs in the paper are quantified on a per unit basis for comparison.

\subsection{Life-Cycle Cost of Sign Sheeting}

For replacing an overhead guide sign with high reflective sheeting, the costs include: sheeting materials and replacement of sign panels. We use three potential prismatic sheeting materials for the analysis. The cost and service life vary with sheeting types, and service life is also different for various environmental conditions. As stated before, higher levels of retroreflectivity are needed to produce equivalent luminance levels by drivers of light trucks than those of passenger cars. Therefore, the service life in Table 4 is based on the analyses from a light truck and for tangent sections of roadways. Based on Fig. 4 and by taking the average of service life for vehicle headlamps US2004 and US2011, the service life values are summarized in Table 4 as well as the unit cost of each sheeting type.

For this analysis, we assume that the currently used material is Type III. When conducting the analysis of other types of sheeting materials, we vary the legend material but keep the background material constantly set as an Type IV material. We consider combinations of materials using Types IV, VIII, and XI for the leg- end. Overhead guide signs are assumed to be in the size of $18 \mathrm{ft}(5.5 \mathrm{~m}) \times 12 \mathrm{ft}(3.7 \mathrm{~m})$. The sheeting used as backgrounds is about the same size as the sign panel and the size of sheeting used to cut legends is assumed to be $8 \mathrm{ft}(2.4 \mathrm{~m}) \times 2 \mathrm{ft}(0.9 \mathrm{~m})$ for three lines. Therefore, the area of sheeting needed for backgrounds is $18 \mathrm{ft}$ $(5.5 \mathrm{~m}) \times 12 \mathrm{ft}(3.7 \mathrm{~m})=216 \mathrm{ft}^{2}\left(20.1 \mathrm{~m}^{2}\right)$ and $3 \times 8 \mathrm{ft}$ $(2.4 \mathrm{~m}) \times 2 \mathrm{ft}(0.9 \mathrm{~m})=48 \mathrm{ft}^{2}\left(4.5 \mathrm{~m}^{2}\right)$ for legends. Accordingly, the sheeting material costs per each sign are calculated for all the potential combinations, listed in Table 5 .

Table 4. Unit cost and service life for different legend sheeting types

\begin{tabular}{|l|c|c|c|}
\hline \multirow{2}{*}{$\begin{array}{c}\text { Legend sheeting } \\
\text { type }\end{array}$} & \multirow{2}{*}{$\begin{array}{c}2011 \text { unit cost } \\
{\left[\$ / \mathrm{ft}^{2}\right]\left[\$ / \mathrm{m}^{2}\right]}\end{array}$} & \multicolumn{2}{|c|}{$\begin{array}{c}\text { Expected service } \\
\text { life [year }]\end{array}$} \\
\cline { 3 - 4 } & & Urban area & Rural area \\
\hline Type III ${ }^{*}$ (in use) & $1.15(12.4)$ & 0 & 20 \\
\hline Type IV & $1.15(12.4)$ & 4 (Fig. 4$)$ & 20 \\
\hline Type VIII & $2.8(30.1)$ & 20 & 20 \\
\hline Type XI & $3.79(40.8)$ & 20 & 20 \\
\hline
\end{tabular}

Note: * shown only for comparisons.

In terms of the costs of sign panel replacement, sign panel overlaying cost is found to be $\$ 30.13 / \mathrm{ft}^{2}$ $\left(\$ 324.3 / \mathrm{m}^{2}\right)$ for overhead signs based on Florida Department of Transportation Maintenance Contract Cost Summary. The approximate cost of replacing an $18 \mathrm{ft}(5.5 \mathrm{~m}) \times 12 \mathrm{ft}(3.7 \mathrm{~m})$ sign is $\$ 30.13 / \mathrm{ft}^{2}$ $\left(\$ 324.3 / \mathrm{m}^{2}\right) \times 216 \mathrm{ft}^{2}\left(20.1 \mathrm{~m}^{2}\right)=\$ 6508$. Accordingly, the total cost of replacing an overhead sign with high reflective sheeting is the sum of the sheeting cost and overlay cost, which is listed in Table 5 as well. The general equation used to calculate the total cost of replacing sign sheeting is shown in Eq. (1). It is noted that other costs are negligible, such as the disposal cost of old sheeting and sign panel and regular maintenance labor cost:

total cost of replacing a sign sheeting = sign area $\times$ background sheeting unit cost + legend area $\times$ legend sheeting unit cost + sign area $\times$

sign panel overlaying unit cost. 
Table 5. Total cost of replacing sign sheeting with various legend sheeting types

\begin{tabular}{|c|c|c|c|c|c|c|}
\hline $\begin{array}{c}\text { Legend sheeting } \\
\text { type }\end{array}$ & $\begin{array}{l}\text { Background } \\
\text { sheeting type }\end{array}$ & $\begin{array}{l}\text { Legend cost per } \\
\text { sign }[\$]\end{array}$ & $\begin{array}{c}\text { Background cost } \\
\text { per sign }[\$]\end{array}$ & $\begin{array}{l}\text { Sheeting cost } \\
\text { per sign }[\$]\end{array}$ & $\begin{array}{l}\text { Overlay } \\
\text { cost }[\$]\end{array}$ & $\begin{array}{c}\text { Total } \\
\text { cost }[\$]\end{array}$ \\
\hline Type IV & \multirow{3}{*}{ Type IV } & 55.2 & 248.4 & 303.6 & \multirow{3}{*}{6508} & 6812 \\
\hline Type VIII & & 134.4 & 248.4 & 382.8 & & 6891 \\
\hline Type XI & & 181.9 & 248.4 & 430.3 & & 6938 \\
\hline
\end{tabular}

Using Eq. (2), the average annual cost for the life cycle of each sheeting material can be calculated by the total costs listed in Table 5 and the service life of sheeting in Table 4. The result is shown in Table 6 for different ambient conditions:

average annual cost of replacing a sign sheeting = total cost of replacing a sign sheeting / sheeting service life.

From Table 6, it is found the annual cost of Type IV sheeting varies in urban and rural areas with the change of service life. In urban area, with external sign lighting, Type IV sheeting is sufficient for 20 years in terms of luminance demands and the annual replacing cost of sheeting drops to the same amount as in rural areas. Among the three sheeting materials, Type IV sheeting has the highest annual cost when used in urban area but has the lowest cost when used in rural area.

Table 6. Average annual cost of replacing sign sheeting with various legend sheeting types

\begin{tabular}{|l|c|c|}
\hline \multirow{2}{*}{$\begin{array}{c}\text { Legend } \\
\text { sheeting type }\end{array}$} & \multicolumn{2}{|c|}{ Annual cost [\$/year] } \\
\cline { 2 - 2 } & Urban area & Rural area \\
\hline \multirow{2}{*}{ Type IV } & $1703^{\star}$ (without sign light) & \multirow{2}{*}{341} \\
\cline { 2 - 2 } & 341 (with sign light) & \\
\hline Type VIII & \multicolumn{2}{|c|}{345} \\
\hline Type XI & 347 \\
\hline
\end{tabular}

Note: ${ }^{\star}$ expected life is 4 years in urban area (Table 4$)$.

\subsection{Life-cycle Cost of Installing Sign Lights}

In addition to the replacement of older sheeting by newer and more efficient sheeting, sign lighting can also be installed in order to meet drivers' visibility demands. For signs which have no sign lighting in use, the costs of installing sign lights include costs of induction or
LED luminaires, cost of Maintenance Of Traffic (MOT), equipment cost, installation labor, operating cost (i.e., electricity cost). The electric power is assumed available at the location of signs without any additional cost for bringing electric service. For the existing signs, which are assumed to have mercury vapor luminaires in use, the costs of replacing the luminaires with induction or LED luminaires include all the above cost except changing the installation labor to retrofitting labor.

For an $18 \mathrm{ft}(5.5 \mathrm{~m}) \times 12 \mathrm{ft}(3.7 \mathrm{~m})$ sign, two luminaires are typically used. The unit costs and service life spans of different types of luminaires are summarized in Table 7. Considering sign lights are turned off during daytime, the lamp life span in hours is converted to the year base using 11 working hours per day. The MOT cost is about $\$ 700$ per sign. The equipment cost and installation labor are about $\$ 900$ for installing two luminaires for signs without sign lighting in use. For signs having mercury vapor luminaires in use, the equipment cost and retrofitting labor to replace with induction or LED luminaires are about $\$ 200$. Thus, the annual installation costs and annual retrofitting cost of two luminaires per sign are averaged by the lamp life span, shown in Table 7 .

The annual electricity cost of two luminaires for each sign is calculated based on the power of each type of luminaire. The unit cost of power is about $\$ 0.143$ per kilowatt hour $[\mathrm{kW} \cdot \mathrm{hr}]$ and sign lights are on for 11 hours per day. For instance, for induction or LED luminaires consuming $100 \mathrm{~W}$ of power, the annual electricity for lighting an overhead sign is $2 \times 100 / 1000 \mathrm{~kW} \times$ 11 hours $/$ day $\times 365$ days/year $\times \$ 0.143 / \mathrm{kW} \cdot \mathrm{hr}=\$ 115 /$ year. The annual electricity costs for each luminaire type are summarized in Table 7. Accordingly, the annual lifecycle cost of newly installed sign lights for each sign is the sum of the annual installation cost and annual electricity cost, as shown in Table 7 as well. Meanwhile,

Table 7. Life-cycle costs of installation/retrofitting sign lights per guide sign

\begin{tabular}{|c|c|c|c|c|c|c|c|c|c|}
\hline $\begin{array}{l}\text { Luminaire } \\
\text { type }\end{array}$ & $\begin{array}{c}\text { Material } \\
\text { cost }[\$]\end{array}$ & $\begin{array}{c}\text { Equipment cost } \\
\text { and installation } \\
\text { labor }[\$]\end{array}$ & $\begin{array}{c}\text { MOT } \\
\text { cost }[\$]\end{array}$ & $\begin{array}{l}\text { Lamp life } \\
\text { span [hr] }\end{array}$ & $\begin{array}{c}\text { Lamp } \\
\text { life span } \\
\text { [year] }\end{array}$ & $\begin{array}{c}\text { Power } \\
{[\mathrm{W}]}\end{array}$ & $\begin{array}{c}\text { Annual } \\
\text { installation } \\
\text { cost }[\$ / \text { year }]\end{array}$ & $\begin{array}{c}\text { Annual } \\
\text { electricity } \\
\text { cost }[\$ / \text { year] }\end{array}$ & $\begin{array}{c}\text { Annual cost } \\
\text { [\$/year] }\end{array}$ \\
\hline \multicolumn{10}{|c|}{ Newly installed sign lights } \\
\hline $\begin{array}{l}\text { Mercury } \\
\text { vapor }^{*}\end{array}$ & 300 & \multirow{2}{*}{900} & \multirow{2}{*}{700} & 24000 & 6.0 & 212 & 93 & 243 & 611 \\
\hline $\begin{array}{l}\text { Induction } \\
\text { or LED }\end{array}$ & 700 & & & 75000 & 18.7 & 100 & 161 & 115 & 275 \\
\hline \multicolumn{10}{|c|}{ Retrofitting existing mercury vapor sign lights } \\
\hline $\begin{array}{l}\text { Induction } \\
\text { or LED }\end{array}$ & 700 & 200 & 700 & 75000 & 18.7 & 100 & 123 & 115 & 238 \\
\hline
\end{tabular}

Note: * shown only for comparison. 
Table 7 also lists the annual life-cycle cost of retrofitted sign lights for each sign, which is the sum of the annual retrofitting cost and annual electricity cost.

In summary, the general equations used for calculating the cost of installation/retrofitting sign lights per guide sign are shown in Eqs (3-5):

$$
\begin{aligned}
& \text { annual installation/retrofitting cost }= \\
& \text { (luminaire number per sign } \times \text { luminaire } \\
& \text { unit cost }+ \text { equipment cost and } \\
& \text { installation labor }+ \text { cost of maintenance } \\
& \text { of traffic) / lamp life span; } \\
& \text { annual electricity cost }=\text { luminaire } \\
& \text { number per sign } \times \text { luminaire electricity } \\
& \text { power } \times \text { annual luminaire working } \\
& \text { hours } \times \text { electricity power unit cost; } \\
& \text { average annual cost of installation/ } \\
& \text { retrofitting sign lights per sign = annual } \\
& \text { installation cost }+ \text { annual electricity cost. }
\end{aligned}
$$

\subsection{Comparison of Life-cycle Costs}

As stated before, for straight and flat roadways, Type VIII and XI sheeting are found to be sufficient for up to 20 years in terms of the required legibility luminance in both rural and urban areas, but Type III and IV sheeting need to be supplemented with sign lighting in order to be used as long as 20 years in urban areas. Therefore, in order to meet sign luminance requirements for 20 years, there are various combinations of sheeting and lighting. Assuming the current Florida Department of Transportation practice is using Type III sheeting for legends, we compared the annual costs of current practice with other possible sheeting/lighting options, as shown in Table 8 .

As shown in Table 8, the annual costs of sheeting and lighting combination are different in urban and rural areas. In rural areas, all the four sheeting materials (Type III, IV, VIII and XI) meet the legibility luminance requirements without sign lighting. However, there are horizontal curve radii where the selection of sign sheeting materials and the need for sign lighting become more limiting (Table 3).

\section{Summary and Conclusions}

By comparing the calculated luminance of a specific sign at a specific situation with the legibility luminance levels required by older drivers, the authors try to identify if high intensity sign sheeting can replace the need for sign lighting; and if not, where overhead signs with lights should be required in lieu of high intensity reflective sheeting in specific locations.

Meanwhile, a life-cycle cost spreadsheet is developed and used to calculate the cost of replacing the current sign sheeting with high reflective sheeting and the cost of installing/upgrading sign lighting. Based on this analysis, it is found that under the conditions considered (either on straight and flat roadways or horizontal curves, in rural areas or urban areas), the most cost effective approach to maintain overhead guide luminance is to use (installing or replacing with) induction or LED luminaires. The results also indicate that a viable alternative (in terms of maintaining luminance and being cost effective) would be to use either Type VIII or Type XI legend sheeting materials and forgo sign lighting. For Type XI sheeting materials, sign lighting would be needed along horizontal curves in rural areas with radii of $880 \mathrm{ft}(268.2 \mathrm{~m})$ and horizontal curves in urban areas with radii of $2500 \mathrm{ft}(762 \mathrm{~m})$ or less.

It needs to be mentioned that the study results are based on some assumptions, which are listed below. With the change of assumptions, the results might alter. However, the study method in the paper is general and sign luminance computation model developed in the paper can be used to evaluate sign legend visibility at various conditions:

\begin{tabular}{|c|c|c|c|}
\hline \multirow{2}{*}{ Current usage } & \multirow{2}{*}{ Treatment } & \multicolumn{2}{|c|}{ Annual cost $[\$ /$ year $]$} \\
\hline & & Urban area & Rural area \\
\hline \multirow{5}{*}{ Type III with no sign lighting } & Install Induction or LED & \multicolumn{2}{|c|}{275} \\
\hline & Replace Type III with IV legends and install Induction or LED & \multicolumn{2}{|c|}{616} \\
\hline & Replace Type III with IV legends & 1703 & 341 \\
\hline & Replace Type III with VIII legends & \multicolumn{2}{|c|}{345} \\
\hline & Replace Type III with XI legends & \multicolumn{2}{|c|}{347} \\
\hline \multirow{4}{*}{$\begin{array}{l}\text { Type III with mercury vapor } \\
\text { sign lighting }\end{array}$} & Replace Mercury vapor with Induction or LED & \multicolumn{2}{|c|}{238} \\
\hline & Replace Type III with IV legends and no light & 1703 & 341 \\
\hline & Replace Type III with VIII legends and no light & \multicolumn{2}{|c|}{345} \\
\hline & Replace Type III with XI legends and no light & \multicolumn{2}{|c|}{347} \\
\hline
\end{tabular}

- a 20 year period is used for analysis; Legibility luminance requirements are based on the 50th percentile levels of elderly drivers' luminance demands;

- recommendations are based on an analysis of legibility for the luminance of the legend, assuming an appropriate contrast ratio supplied by retroreflective background materials; however, the analysis is not dependent on the specific types of retroreflective material used on the background;

Table 8. Cost of different combinations of legend sheeting and lighting on straight and flat roadways

Note: the treatments assume an appropriate background material is used to provide adequate contrast. 
- the sign and the vehicle are assumed to be in the same lane;

- maintenance costs associated with sheeting and sign lighting are not included in the life-cycle cost analysis;

- the current in-service legend sheeting and sign lighting is assumed to be Type III legend sheeting without sign lighting or Type III legend sheeting with mercury vapor luminaire;

- in the cost study, sign size is assumed to be $18 \mathrm{ft}$ $(5.5 \mathrm{~m}) \times 12 \mathrm{ft}(3.7 \mathrm{~m})$, and two luminaires per sign are assumed.

\section{Acknowledgements}

The authors would like to express our gratitude to the Florida Department of Transportation for sponsoring the research. The authors also thank Richard I. Kerr and Chester A. Henson of the Florida Department of Transportation for their input and assistance in this work.

\section{References}

AASHTO. 2005. Roadway Lighting: Design Guide. American Association of State Highways and Transportation Officials (AASHTO), Washington, DC (2005 Edition). 128 p. Available from Internet: https://bookstore.transportation.org/ item_details.aspx?ID=1412

ASTM D4956-09e1:2009. Standard Specification for Retroreflective Sheeting for Traffic Control. http://doi.org/10.1520/D4956-09

Bullough, J. D.; Skinner, N. P.; O’Rourke, C. P. 2010. Legibility of urban highway traffic signs using new retroreflective materials, Transport 25(3): 229-236. http://doi.org/10.3846/transport.2010.28

Carlson, P. J.; Hawkins, H. G. 2003. Minimum Retroreflectivity Levels for Overhead Guide Signs and Street-Name Signs. Report No FHWA-RD-03-082. Federal Highway Administration, McLean, VA, US. 120 p. Available from Internet: https://www.fhwa.dot.gov/publications/research/ safety/03082/03082.pdf

FHWA. 2009. Manual on Uniform Traffic Control Devices for Streets and Highways. Federal Highway Administration (FHWA), US Department of Transportation, Washington, DC. 862 p. Available from Internet: http://mutcd.fhwa.dot. gov/pdfs/2009r1r2/pdf_index.htm

Holick, A. J.; Carlson, P. J. 2008. Minimum Retroreflectivity Levels for Blue and Brown Traffic Signs. Report No FHWAHRT-08-029. Federal Highway Administration, McLean, VA, US. 51 p. Available from Internet: http://www.fhwa. dot.gov/publications/research/safety/08029/08029.pdf

IESNA. 2001. IESNA Recommended Practice for Roadway Sign Lighting. IESNA RP-19-01. Illuminating Engineering Society of North America, New York, NY. 16 p.

INDOT. 2009. Field Evaluation of Unlighted Overhead Guide Signs. Indiana Department of Transportation (INDOT), Indianapolis, Indiana, US.

Jackson, N. M.; Carlson, P. J.; Ye, F.; Jackson, G. R. 2013. Use of High Intensity Reflective Sheeting in-lieu of External Lighting of Overhead Roadway Signs. Report No BDK82 977-07. Florida Department of Transportation, Tallahassee, FL, US. 82 p. Available from Internet: http://www.fdot.gov/ research/completed_proj/summary_mnt/fdot-bdk82-97707-rpt.pdf
Schoettle, B.; Flannagan, M. J. 2011. A Market-Weighted Description of Low-Beam and High-Beam Headlighting Patterns in the U.S.: 2011. Report No. UMTRI-2011-33. University of Michigan, US. 30 p.

Schoettle, B.; Sivak, M.; Flannagan, M. J.; Kosmatka, W. J. 2004. A Market-Weighted Description of Low-Beam Headlighting Patterns in the U.S.: 2004. Report No. UMTRI-2004-23. University of Michigan, US. 18 p. Available from Internet: https://deepblue.lib.umich.edu/bitstream/handle/2027.42/55198/UMTRI-2004-23.pdf 